\title{
Rancang Bangun Receiver Sinyal ADS-B Pesawat Menggunakan RTL-SDR serta Antena $1090 \mathrm{MHz}$
}

\author{
Fery Irawan \\ Jurusan Teknik Elektro, \\ Program Studi Teknik \\ Telekomunikasi D IV \\ Politeknik Negeri Sriwijaya \\ Palembang, Indonesia \\ feryyirawan10@gmail.com
}

\author{
Ciksadan \\ Jurusan Teknik Elektro, \\ Program Studi Teknik \\ Telekomunikasi D IV \\ Politeknik Negeri Sriwijaya \\ Palembang, Indonesia \\ ciksadanc@gmail.com
}

\author{
Suroso \\ Jurusan Teknik Elektro, \\ Program Studi Teknik \\ Telekomunikasi D IV \\ Politeknik Negeri Sriwijaya \\ Palembang, Indonesia \\ osorus11@gmail.com
}

\begin{abstract}
Automatic Dependent Surveillance Broadcast $(A D S-B)$ is a surveillance technology used in air navigation. This technology can view information in the form of 24 bit ICAO aircraft addresses, ident or squawk, latitude, altitude, nationality, speed, longitude, track and heading. The current development problem can only be done with the Flight Radar24 web-based application, so it requires an internet connection to operate. To solve this problem, the necessary hardware is needed that can receive $A D S-B$ signal with a frequency of $1090 \mathrm{MHz}$ and can translate it into information. The RTL-SDR R820T2 is a software-based hardware device that can receive a wide range of signals from $25 \mathrm{MHz}-1700 \mathrm{MHz}$. To maximize signal reception, an additional omnidirectional antenna is capable of receiving signals from all directions. With this system, it is expected to make it easier to fly directly without an internet connection.
\end{abstract}

Keywords- Automatic Dependent Surveillance Broadcast, RTL-SDR R820T2, Antena

\section{PENDAHULUAN}

Kemajuan teknologi yang pesat saat ini telah mendorong kemajuan baru pada berbagai bidang sains, terutama salah satunya adalah pada bidang komunikasi radio. Perkembangan pada bidang komunikasi tersebut menjadi sorotan serius dalam perkembangan teknologi pada pelayanan navigasi penerbangan. Penggunaan peralatan navigasi penerbangan yang mulanya menggunakan radar perlahan mulai beralih ke Automatic Dependent Surveillance-Broadcast (ADSB)[1].

Automatic Dependent Surveillance Broadcast adalah sebuah sistem pemantauan (surveillance) yang diterapkan pada penerbangan nir radar untuk tujuan keselamatan dan pemantauan pada bidang penerbangan. Pesawat udara dilengkapi dengan sebuah transponder yang memungkinkan pengiriman data penerbangan secara otomatis. Data penerbangan berupa posisi dan kecepatan diperoleh dari sistem satelit navigasi GNSS (Global Navigation Satellite System)[2]. Salah satu permasalahan yang dihadapi dalam perkembangan teknologi Automatic Dependent Surveillance-Broadcast yaitu bagaimana mendeteksi serta memantau pesawat dengan teknologi peralatan yang murah dibanding peralatan ADS-B yang ada di bandara. Sedangkan untuk masyarakat awam pemantauan penerbangan dapat diakses secara bebas menggunakan aplikasi berbasis web FlightRadar24, hanya saja aplikasi ini membutuhkan jaringan internet dalam penggunaannya.

Sinyal ADS-B berfrekuensi $1090 \mathrm{MHz}$ dengan cakupan maksimum pancaran ke Ground Statiton ADS-B hingga 200 NM (370 km)[3]. Untuk dapat menerima data sinyal yang berfrekuensi 1090 $\mathrm{MHz}$ serta menterjemahkannya dalam bentuk RAW data, maka diperlukan perangkat SDR (Software Defined Radio)

RTL-SDR R820T2 merupakan salah satu perangkat Software Defined Radio yang mampu menangkap sinyal radio dari frekuensi dan modulasi tertentu[4]. Sistem ini tentunya memerlukan perangkat keras tambahan berupa antena jenis omnidirectional yang memiliki bentuk monopole dengan frekuensi kerja pada $1090 \mathrm{MHz}$, Serta software RTL1090 dan Adsbscope yang digunakan sebagai decode sinyal.

Rancangan receiver sinyal ADS-B menggunakan perangkat receiver yang berbasis komputer yaitu RTL-SDR R820T2, dengan penambahan antena omnidirectional $1090 \mathrm{MHz}$ untuk memaksimalkan kerja peralatan receiver. Aplikasi RTL1090 dan Adsbscope sebagai pembaca sinyal $1090 \mathrm{MHz}$ sehingga dapat mengetahui data ADSB yang berupa 24 bit ICAO aircraft address, Nationality, Ident atau Squawk, Altitude, Latitude, Longitude, Speed, Heading dan Track.

\section{DASAR TEORI}

Automatic Dependent Surveillance - Broadcast adalah sebuah teknologi surveillance yang menggunakan informasi posisi dari satelit yang dipancarkan secara terus-menerus, berbeda terbalik dengan teknologi radar yang menggunakan sistem scan target pesawat. Pesawat yang memiliki 


\section{Rancang Bangun Receiver Sinyal ADS-B Pesawat Menggunakan RTL-SDR serta Antena 1090 MHz}

perangkat ADS-B transponder akan memancarkan informasi dari Flight Management System secara terus menerus[5].

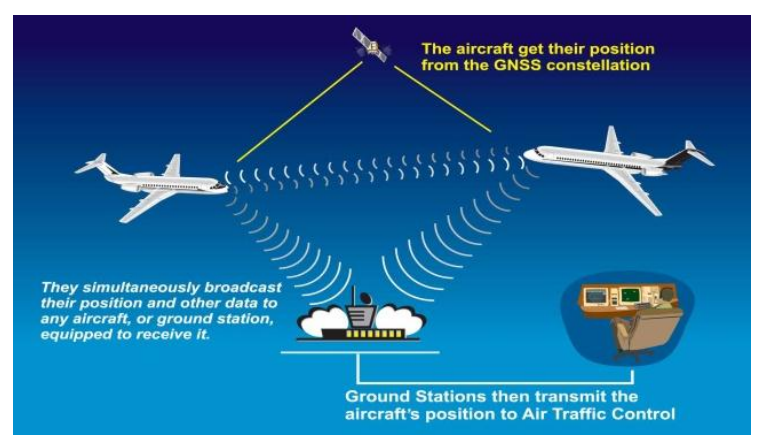

Gambar 1. Teknologi ADS-B

Software Defined Radio (SDR) merupakan teknologi yang berkembang pesat saat ini terutama dalam industri telekomunikasi. SDR bertujuan untuk memaksimalkan progammable hardware untuk membangun radio yang berbasis software[6].

RTL-SDR R820T2 merupakan salah satu jenis Software Defined Radio (SDR) yang dapat digunakan untuk menangkap gelombang radio dengan menggunakan USB Tuner dan komputer sebagai pengoprasiannya.

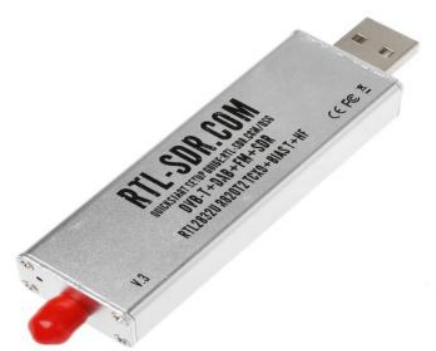

Gambar 2. RTL-SDR R820T2

Antena adalah komponen terpenting dalam transmisi. Antena adalah perangkat yang dirancang untuk dapat menerima ataupun memancarkan gelombang elektromaknetik[7].

omnidirectional merupakan jenis antena yang memiliki pancaran atau penerimaan sinyal kesegala arah dengan daya yang sama. Antena omnidirectional biasanya digunakan pada lingkup base station terbatas dan cenderung untuk posisi pelanggan yang melebar[8].

Antena omnidirectional pada rancangan ini menggunakan kabel coaxial. Setiap elemen pada kebel coaxial dengan panjang mengikuti panjang gelombang yang diinginkan dengan rumus yang sudah di tetapkan untuk perhitungan antena.

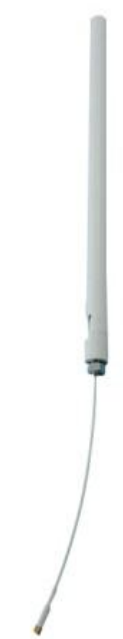

Gambar 3. Antena Omnidirectional

Aplikasi ini digunakan untuk mengetahui sinyal $1090 \mathrm{MHz}$ yang di dapat, serta menterjemahkan data sinyal yang diterima oleh SDR.

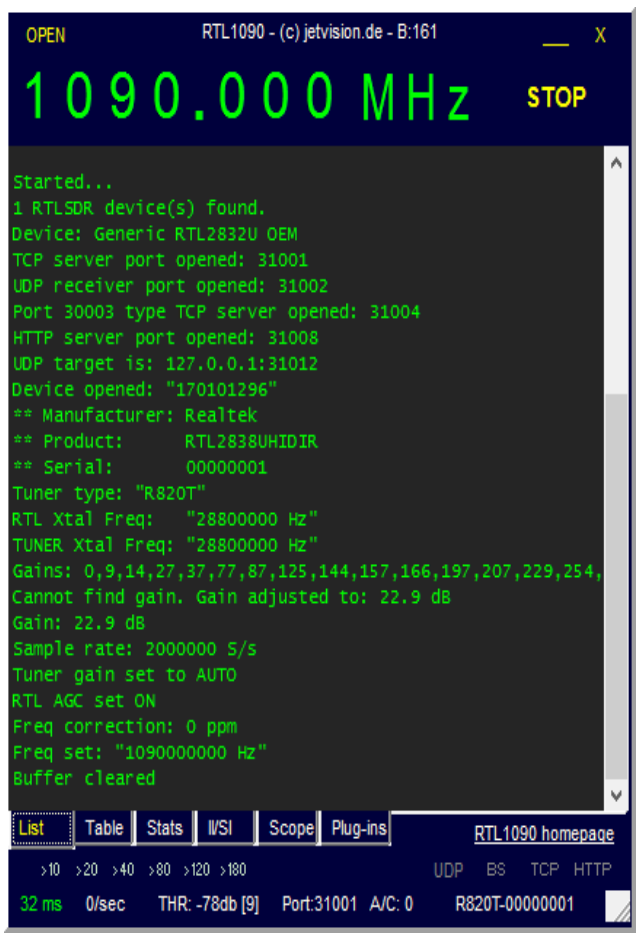

Gambar 4. Aplikasi rtl1090

Aplikasi ini digunakan untuk memonitor pesawat serta menterjemahkan informasi. Hasil data berupa tampilan target pesawat yang didapat dari hasil pemrosesan aplikasi rtl 1090 sebelumnya. 


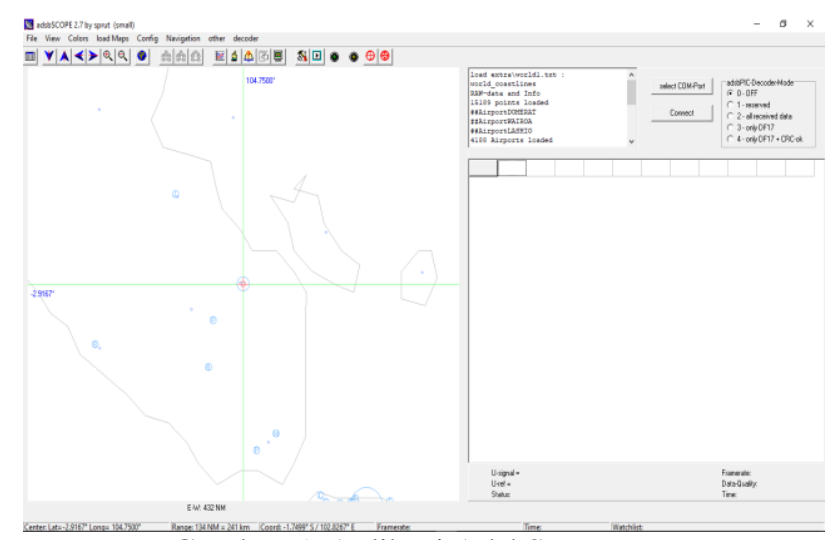

Gambar 5. Aplikasi AdsbScopee

\section{METODE PENELITIAN}

A. Kerangka Penelitian

Tahapan kerangka penelitian dapat dilihat pada gambar berikut.

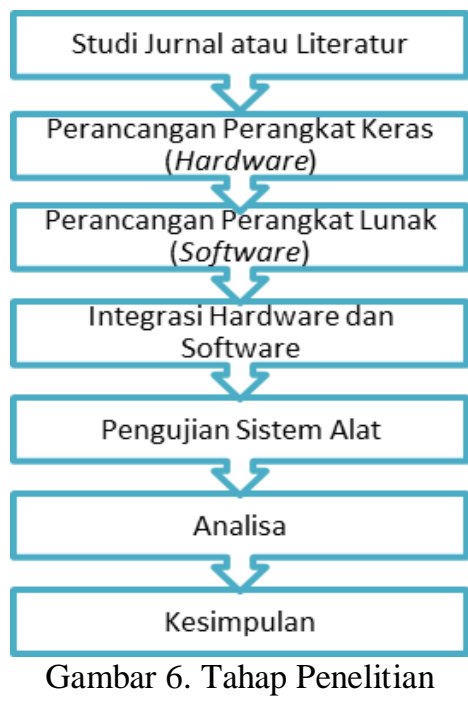

Dari gambar diatas, dapat diketahui bahwa tahap keseluruhan penelitian dimulai dari tahap sebagai berikut.

1. Studi Jurnal atau Literatur

Pada tahap ini penulis membaca dan mempelajari literatur yang relevan sesuai dengan masalah yang akan dibahas. Studi literatur dilakukan dengan cara menelusuri sumber-sumber baik dari jurnal, buku, maupun sumber terpercaya dari internet. Pada tahap ini diketahui masalah pada rancangan teknologi ADS-B, mulai perancangan yang membutuhkan banyak biaya, dan ketergantungan pada koneksi internet saat pengaplikasiannya. Maka dengan adanya studi literatur diharapkan dapat dilakukan pembaharuan untuk penelitian selanjutnya.

2. Perancangan Perangkat Keras

Pada tahapan ini, penulis akan merancang sesuai dengan kebutuhan alat. Pada sistem ini digunakan RTL-SDR R820T2 sebagai receiver yang dapat digunakan untuk merima sinyal dengan cakupan yang cukup luas, penambahan perangakat keras seperti antena agar memaksimalkan kinerja receiver tersebut. Perancangan perangkat keras dapat dilihat pada diagram berikut.

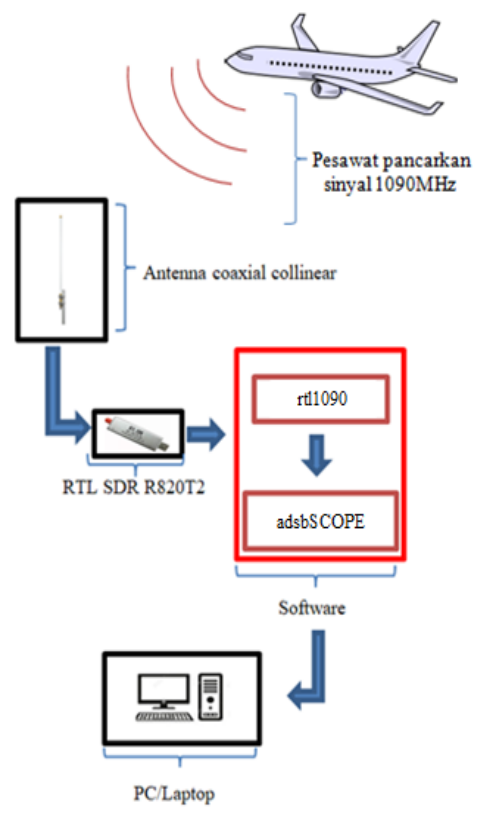

Gambar 7. Perancangan Perangkat Keras

3. Perancangan Perangkat Lunak

Pada tahapan ini, penulis menngunakan dua perangkat lunak (software), rt11090 dan adsbSCOPE. RTL 1090 berfungsi untuk menampilkan data sinyal yang diperoleh, sedangkah adsbSCOPE berguna untuk menterjemankan data sinyal menjadi informasi Map target/pesawat yang ada di udara[9]. Berikut diaram perancangan perangkat lunak.

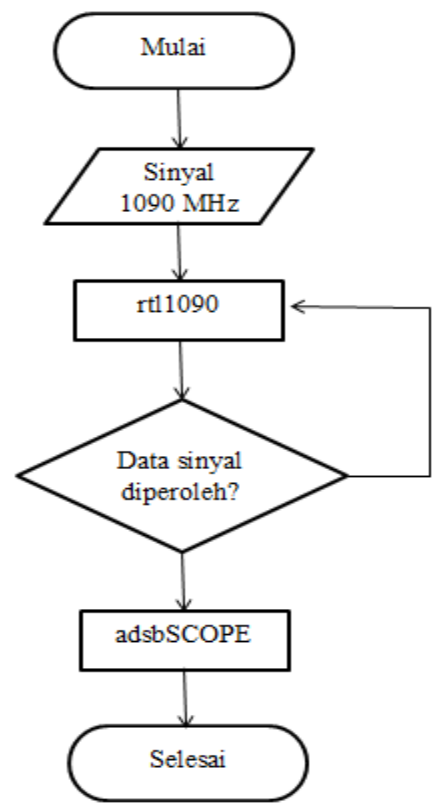

Gambar 8. Flow Chart Perangkat Lunak 


\section{Rancang Bangun Receiver Sinyal ADS-B Pesawat Menggunakan RTL-SDR serta Antena 1090 MHz}

4. Integrasi Hardware dan Software

Pada tahap ini, penulis menggabungkan kedua elemen hardware dan software sehingga dapat bekerja dengan baik dan terintegrasi.

5. Pengujian Sistem Alat

Pada tahap ini, penulis menguji alat yang sudah terintegrasi untuk mengetahui dan menguji fungsi dari alat yang telah dibangun. Parameter yang akan diujikan berupa 24 bit ICAO aircraft address, ident atau squawk, latitude, altitude, nationality, speed, longitude, track serta heading.

6. Analisa

Pada bagian ini, penulis melakukan analisa dan pengkajian terhadap alat yang telah selesai dibuat dan diuji.

7. Kesimpulan

Pada tahap ini, penulis merangkum tentang aspek yang ada pada penelitian dan menyimpulkannya secara singkat dan jelas.

\section{HASIL DAN PEMBAHASAN}

A. Pengaturan Software

Instalasi Zadig

Instalasi Zadig bertujuan agar perangkat USB RTL-SDR dapat di akses menggunakan komputer[10].

a) Hubungkan RTL-SDR pada komputer.

b) Install file install-rtlsdr.bat untuk mendownload driver.

c) Buka file zadig.exe, lalu pilih options dan pilih list all device.

d) Pilih Bulk-In, Interface, pastikan pilih interface 0 . Kemudian klik replace driver tunggu hingga instalasi selesai. berikut tampilan zadig setelah penginstallan.

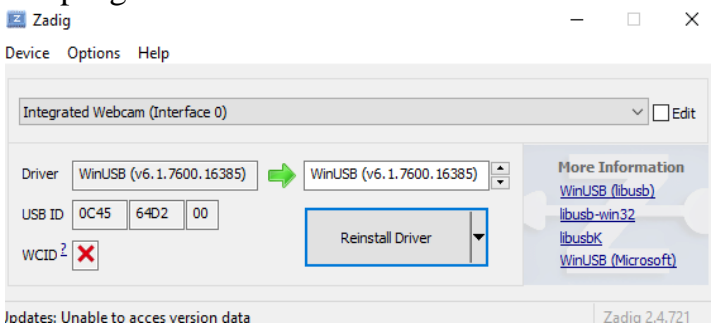

Gambar 9. Tampilan zadig setelah penginstallan

Pengaturan rtl1090MHz

a) Install $\mathrm{rt} 11090 \mathrm{MHz}$

b) Hubungkan RTL-SDR pada komputer.

c) Buka aplikasi rt11090, lalu klik start. Jika berhasih maka akan muncul tampilan berikut.

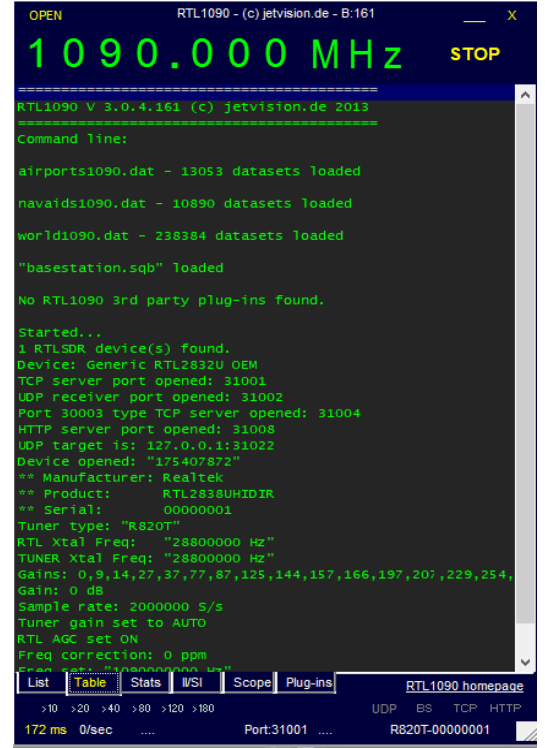

Gambar 10. Tampilan rtl1090 yang sudah terhubung ke RTL-SDR

Pengaturan adsbSCOPE

a) Install adsbSCOPE

b) Buka aplikasi adsbSCOPE, kemudian ke other, lalu network, network setup, kemudian ubah URL local menjadi 127.0.0.1 dan port number sesuai port pada aplikasi rtl1090, lalu pilih RTL1090

c) Pilih other kembali, lalu pilih RAW-Data client aktif, tunggu hingga connected.

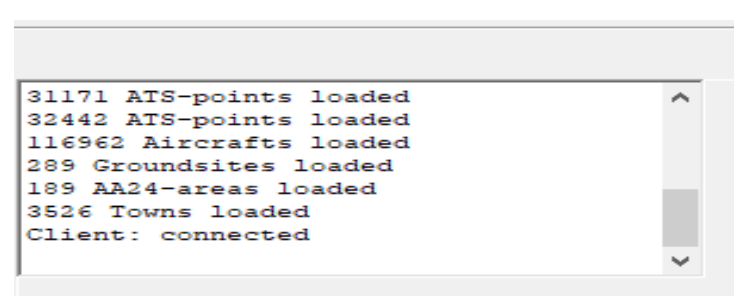

Gambar 11. Tampilan adsbSCOPE yang telah connected

B. Perancangan Perangkat keras (Hardware) Perancangan Antena Omnidirectional

Pada pernacangan antena ini bahan utama yang digunakan adalah kabel coaxial yang memiliki velocity factor sebesar $84 \%$.

Rumus perhitungan panjang elemen:

$$
\begin{aligned}
& \chi=C / f \\
& \mathrm{~L}=0.5 \times k \times \chi
\end{aligned}
$$

$f=$ Frekuensi kerja yang dinginkan

$\chi=$ Panjang gelombang

$C=$ Cepat rambat cahaya $(300000000 \mathrm{~m} / \mathrm{s})$

$\mathrm{L}=$ Panjang elemen

$\mathrm{K}=$ Velocity factor $(0,84)$

Jadi cepatan rambat sinyal pada kabel adalah

$300000000 \mathrm{~m} / \mathrm{s} \times 84 \%$

$\chi=C / f=30000000 / 1090000000$ 


\section{Rancang Bangun Receiver Sinyal ADS-B Pesawat Menggunakan RTL-SDR serta Antena 1090 MHz}

$$
\begin{aligned}
\mathrm{L} & =0.5 \times k \times \chi \\
& =0,5 \times 0,84 \times 300 / 1090 \\
& =11,6 \mathrm{~cm}
\end{aligned}
$$

Jadi elemen coaxial yang diperlukan masing - masing sepanjang 11,6 cm.

Pada perancangan antena ini elemen yang di pakai sebanyak 8 buah dengan panjang masingmasing elemen $11,6 \mathrm{~cm}$

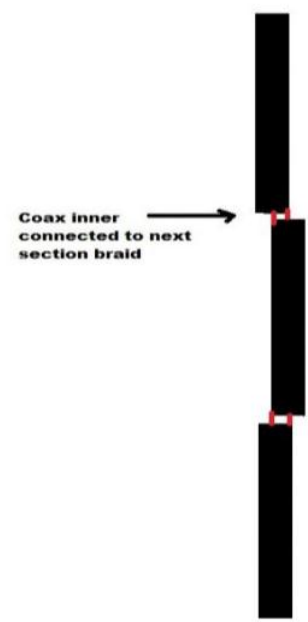

Gambar 12. Penghubungan Tiap elemen antena

Perancangan Perangkat Keras Keseluruhan

Perancangan hardware receiver sinyal ADS-B yang telah berhasil dibuat berdasarkan rancangan, sehingga dapat berkerja secara integrasi dengan software.

Hasil dari perancangan perangkat keras (hardware) dapat dilihat pada gambar berikut.

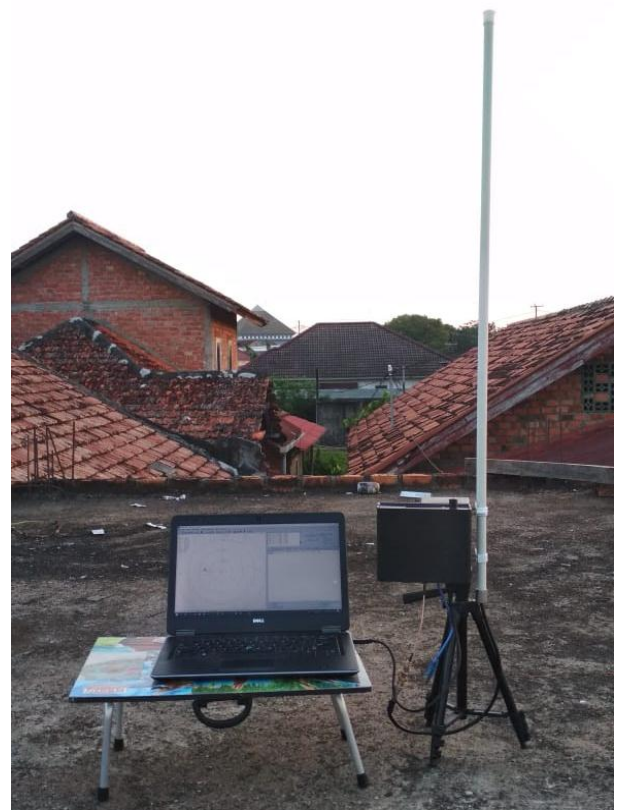

Gambar 13. Tampak depan hasil perangkat keras

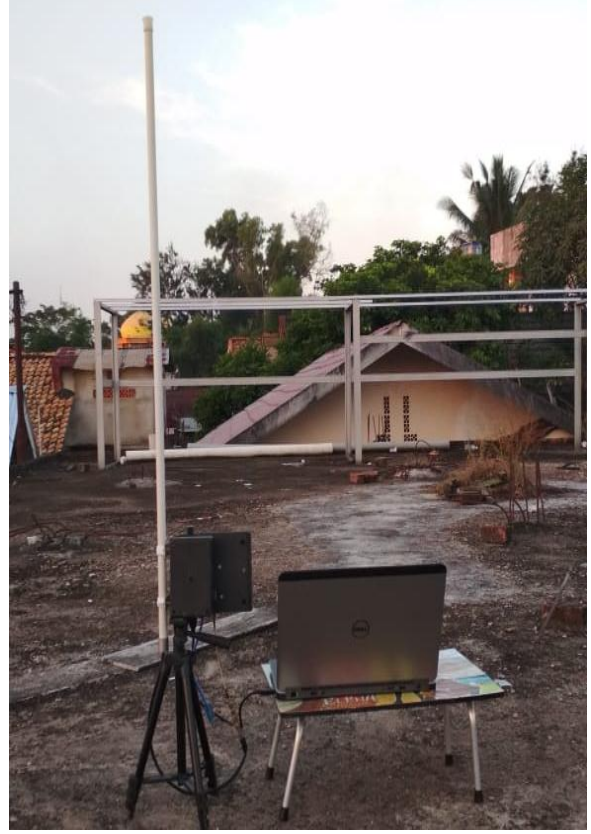

Gambar 14. Tampak belakang hasil perangkat keras

\section{Pengujian}

Pada tahap pengujian, perangkat keras dihubungkan ke komputer yang telah diinstall software rt11090 dan adsbSCOPE. Dalam pengujian yang dilakukan pada hari jumat tanggal 31 juli 2020, pukul 17:48 WIB di kota palembang diperoleh hasil sebagai berikut.

\section{1. rt11090}

Pada aplikasi ini dapat diketahui sinyal $1090 \mathrm{MHz}$ yang diperoleh dari perangkat receiver sinyal ADS-B. Berikut data yang diperoleh.

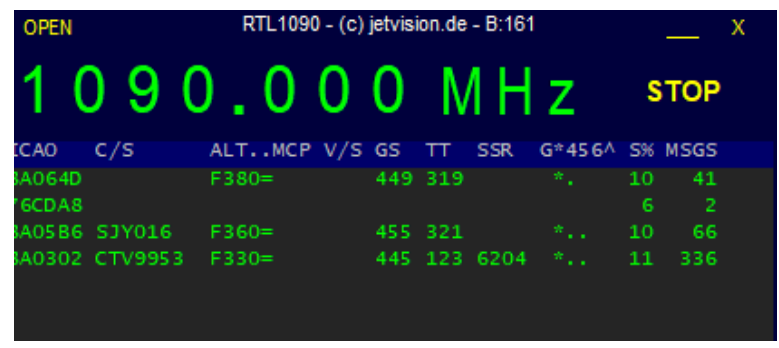

Gambar 15. Data sinyal $1090 \mathrm{MHz}$

2. adsbSCOPE

Pada aplikasi ini sinyal ADS-B akan diterjemahkan menjadi informasi sebagai berikut.

\begin{tabular}{|l|l|l|l|l|l|l|l|l|l|l|l|}
\hline Nr. & ICA024 & Regist. & Ident & A.1t & Lat & Long & Speed & Head. & Climb & Type & T-out \\
\hline 5 & 8A064D & Indonesia & & 38000 & -3.59 & 104.92 & 449 & 319 & & & 3 \\
\hline 4 & 8 AA05B6 & Indonesia & SJY016 & 35975 & -3.50 & 104.63 & 454 & 321 & & & 0 \\
\hline 3 & $76 C D A 8$ & Singapore & & & & & & & & & 8 \\
\hline 2 & C03D27 & Canada & CFXBC & 1000 & -2.93 & 104.70 & 86 & 31 & 64 & & $295 \mathrm{M}$ \\
\hline 1 & $7502 D 9$ & Malaysia & IXD319 & 40000 & & & 428 & 341 & & & $122 \mathrm{M}$ \\
\hline 0 & 8A0302 & PR-GLJ & CTV9953 & 33000 & -2.86 & 104.38 & 445 & 123 & & A320 & $23 \mathrm{M}$ \\
\hline
\end{tabular}

Gambar 16. Data dalam bentuk informasi 


\section{Rancang Bangun Receiver Sinyal ADS-B Pesawat Menggunakan RTL-SDR serta Antena 1090 MHz}

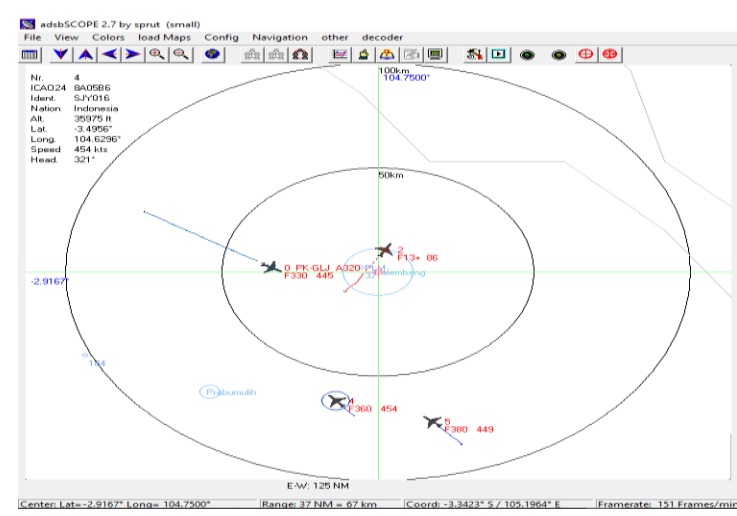

Gambar 17. Data dalam bentuk Map

Data informasi yang diperoleh dari salah satu pesawat sebagi berikut.

Tabel 1. Data informasi salah satu pesawat

\begin{tabular}{|l|l|}
\hline \multicolumn{1}{|c|}{ Parameter } & \multicolumn{1}{c|}{ Informasi } \\
\hline ICAO24 & $8 \mathrm{~A} 05 \mathrm{~B} 6$ \\
\hline Identity & SJY016 \\
\hline Nation & Indonesia \\
\hline Altitude & $35975 \mathrm{ft}$ \\
\hline latitude & $-3.4956^{\circ}$ \\
\hline Longitude & $104.6296^{\circ}$ \\
\hline Speed & $454 \mathrm{kts}$ \\
\hline Heading & $321^{\circ}$ \\
\hline
\end{tabular}

\section{KESIMPULAN}

Berdasarakan hasil dari rancang bangun receiver sinyal ADS-B pesawat dapat disimpulkan bahwa, receiver sinyal ADS-B ini menggunakan RTL-SDR Serta Antena Coaxial Collinear $1090 \mathrm{MHz}$ sebagai receiver sinyal, dan untuk interfacenya menggunakan Software rtl1090 dan adsbSCOPE yang berfungsi sebagai penerjemah sinyal ADS-B yang berfrekuensi $1090 \mathrm{MHz}$. Integrasi software dan hardware pada rancang bangun receiver sinyal ADSB pesawat dapat menghasilkan informasi berupa 24 bit ICAO aircraft address, ident atau squawk, latitude, altitude, nationality, speed, longitude, track serta heading.

\section{DAFTAR PUSTAKA}

[1] Yati,N. dan Susanti. (2014) "WARTA ARDHIA Jurnal Perhubungan Udara: Implementasi Automatic Dependent Surveillance Broadcast (ADS-B) di Indonesia" Vol. 40:147-162.

[2] Pusat teknologi Elektronika. (2018) "Automatic Dependent Surveillance- Broadcast (ADS-B)" https://pte.bppt.

go.id/tentangkami/portofolio/automaticdependent-surveillance-broadcast-ads-b

[3] Feti, Fatonah. et.all (2016). Jurnal Ilmiah Aviasi Langit Biru "Rancangan Antena MonopolePeralatan Receiver Automatic
Dependent Surveillance Broadcast (ADS-B) Sebagai Alat Bantu Pembelajarandi Program Studi Teknik Telekomunikasidan Navigasi Udara Sekolah Tinggi Penerbangan Indonesia". Vol. 9-66.

[4] Ifroh, Malia et.all. (2015) "Implementasi Gnuradio GR-DVBT Untuk Decoding Sinyal Televisi Digital". VOL. 1, PAGE 2153.

[5] Bagus, Bambang et.all. (2019) "Studi Ekperimental Penerima ADS-B Menggunakan RTL 1090 dan RTLSDR R820T2 di Bandara Juanda Surabaya".

[6] Slamet, Djoni et.all. (2018) "Rancangan Receiver Automatic Dependent Surveillance Broadcast (ADS-B) Menggunakan RTL-SDR R820T2 Guna Meningkatkan Pelayanan Navigasi Penerbangan di Bandar Udara Internasional Lombok". Vol. 2 No. 2 Oktober 2018.

[7] Windi,K (2018)"'Rancang Bangun Antena 2,4 GHz Untuk Jaringan Wireless LAN"

[8] PUSATRIK.COM. (2018). "PERBEDAAN ANTENA DIRECTIONAL DAN OMNIDIRECTIONAL."HTTPS://WWW.PUSATRIK.COM /2018/05/PERBEDAAN-ANTENA-DIRECTIONALDAN.HTML.

[9] Azis,A dan Rio,S (2019). "Rancangan Antena Penerima Automatic Dependent Survaeillance Broadcast Dengan Frekuensi 1090MHz Menggunakan RTL820T" Volume II Nomor 1.

[10] TRENDBLOG. (2018). "Install Driver USBASP"http://www.technoriderproject.com/2 018/02/install-driver-usb-asp. html 